\title{
O D.A.S.P. no II Congresso Ibero-Americano de Municipios
}

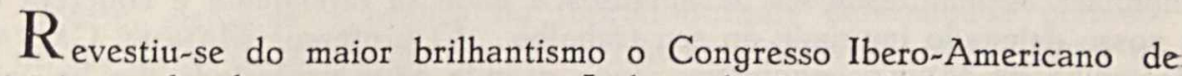
Municipios realizado recentemente, em Lisboa, de 14 a 19 de maio último. Pode dizer-se que os seus resultados surpreenderam a todos os observadores afeitos a reunióes internacionais de estudos e debates.

O noticiário da imprensa internacional é altamente significativo a êsse respeito. Ao contrário do que tem ocorrido em relação a certos conclaves de âmbito mundial, nenhuma palavra de reserva foi pronunciada pondo em dúvida a eficiência dos trabalhos do Congresso de Lisboa, ou as soluções dêle decorrentes. A presença de consagradas autoridades nos temas ali discutidos, os catedráticos mais renomados internacionalmente, explica o êxito marcado pelo certame no campo do municipalismo.

O D.A.S.P., distinguido com honroso convite feito pessoalmente ao Excelentíssimo Senhor Diretor-Geral, Dr. JoÃo Guilherme de Aragão, estêve, por determinação dêste, na impossibilidade de ausentar-se no momento do pais, representado pelo Dr. Manoel Caetano Bandeira de Mello, Diretor do Serviço de Documentação. Defensor entusiasta dos ideais municipalisteas, estava plenamente autorizado o Dr. Manoel Caetano Bandeira. DE MELlo para cumprir a brilhante e segura atuação, que foi a sua, tanto nas comissões técnicas como no plenário do Congresso.

Como Relator de um dos quatro temas em debate - ao lado dos Delegados de Portugal, Espanha e Argentina, firmou-se, imediatamente, como um dos representantes mais categorizados. Seu trabalho "Formação e Aperfeiçoamento do Funcionário da Administração Local" soube traduzir, com extraordinária lucidez, tôda a experiência brasileira na matéria, de tal maneira que se constituiu numa autêntica contribuição do D.A.S.P. à discussão dos problemas de natureza municipalista.

Conceitos sôbre a seleção e o aperfeiçoamento de pessoal, a classificação dos cargos, ou ainda a análise e intransigente defesa do sistema do mérito no recrutamento dos funcionários, o que constitui a grande bandeira do D.A.S.P., - imprimiram ao trabalho, elaborado de acôrdo com as diretrizes diretamente traçadas pelo Dr. JoÃo Guilherme DE ArAgão, uma consistência que se impôs, desde logo, à atenção das diversas delegações participantes do Congresso. Foi, por isso mesmo, unânime a aprovação dêste às conclusões encerradas no excelente relatório do representante brasileiro, que obteve ainda os maiores triunfos oratórios em Lisboa, Coimbra e na Espanha.

A imprensa de Lisboa não lhe poupou elogios à firme conduta, ao extraordinário espirito de sintese no elaborar as conclusões decorrentes das discus- 
sões nos órgãos técnicos e no plenário, e às declarações que formulou perante o Congresso.

Vale, igualmente, por uma consagração o que, a seu respeito, disseram os demais componentes da nossa delegação. Do Deputado Federal Lourival Batista, eminente representante do Estado de Sergipe, são estas palavras ditadas ao "O Jornal", da Capital da República, "Esta última tese (refere-se ao trabalho «Formação e Aperfeiçoamento do Funcionário da Administração Local») foi relatada pelo Delegado brasileiro, professor Manoel Caetano Bandeira de Melio, do D.A.S.P., que logrou os maiores elogios. Eram unânimes as manifestações de aplausos à maneira inteligente e concreta que o nosso delegado imprimiu ao seu trabalho. O professor Manoel Caetano BANDEIRA DE Mello conquistou ainda grande êxito proferindo um belíssimo discurso em Coimbra».

O Deputado estadual Almir Pinto, Presidente da Assembléia Legislativa do Ceará, teve, igualmente, palavras de louvor ao representante do D.A.S.P., em sua entrevista ao "Correio do Ceará». Para os vereadores Nilson Gontijo e José Greco, da Câmara de Vereadores de Belo Horizonte, a tese do Dr. Manoel Caetano Bandeira de Mello foi «a melhor do certame, ou, pelo menos, a mais comentada e louvada pela imprensa lisboeta» («Fôlha de Minas»).

Ao transcrevermos as conclusões do trabalho apresentado ao Congresso de Lisboa, queremos registrar, com a devida homenagem, o êxito da missão cumprida pelo Diretor do Serviço de Documentação do D.A.S.P., Doutor Manoel Caetano Bandeira de Mello.

\section{FORMAÇÃO E APERFEIÇOAMENTO DO FUNCIONÁRIO DA ADMINISTRAÇÃO LOCAL}

Conclusoes apresentadas pelo Dr. Manoel Caetano Bandeira de Mello e aprovadas pelo II Congresso Ibero-Americano de Municipios ( ${ }^{*}$ )

1. O recrutamento, seleção, formação e aperfeiçoamento dos efetivos humanos constituem aspectos decisivos para a segurança e o bem-estar da coletividade;

2. As municipalidades, que não o possuírem, deverão organizar serviço ou órgão de pessoal, de conformidade com as suas necessidades e possibilidades;

3. Para estabelecer ordem autêntica na administração, impõe-se a instituição de um plano de classificação, contendo as especificações legais das funções e dos cargos;

4. Os diplomas conferidos pelas escolas públicas ou reconhecidas pelo Estado, especialmente no ensino superior e médio, apesar de nem sempre poderem elas orientar a sua docência no sentido de apropriado conhecimento da furção pública, constituem ainda um meio mais conveniente de prévia formação dos possiveis aspirantes aos postos de funcionários administrativos e técnicos dos quadros locais. Daí preconizar-se a conveniência de títulos,

(*) Transcrito do "Diário de Notícias", de Lisboa, de 20-5-59. 
dessas Universidades e Escolas, notadamente, o que seria mais desejável e de maior importância, certificados fornecidos por escolas de administração local;

5. O sistema do mérito é o melhor método de seleção do funcionalismo, seja qual fôr a categoria do mesmo. A acepção da palavra mérito abrange, não só os conhecimentos gerais e especiais adequados a cada função, mas ainda as qualidades pessoais especificamente indispensáveis para o seu bom exercício. O mérito deve ser aferido através de provas públicas, abertas a todos os cidadãos indiscriminadamente, independentemente de quaisquer preconceitos de raça, côr, religião ou influências politicas, ou de qualquer outra espécie, mediante a prática na função durante determinado período, a fim de avaliar-se da adaptação do pessoal às exigências do cargo. Quer na fase de provas de seleção, quer no período experimental, cumpre submeter o candidato a testes de capacidade e de comportamento perante o público, de que o funcionário é mero servidor;

6. Terminada a fase de seleção para a admissão, cumpre conferir ao funcionário os meios necessários para o seu aperfeiçoamento, como sejam a assistência a conferências, cursos de administração, colóquios periódicos, bôlsas de estudo, prêmios de aperfeiçoamento e outras formas de elevação do nivel de conhecimentos gerais e específicos das funções, inclusive cursos por correspondência, a fim de eliminar-se o inçonveniente das distâncias;

7. Recomenda-se a elaboração e vigência, onde não exista, do Estatuto dos Funcionários Municipais, em que se fixem os seus deveres e os seus direitos a remuneração condigna, de modo a poderem dar às respectivas tarefas o tempo integral assinalado, e

8. Não obstante a diferença das funções públicas do Estado e do Municipio, caberia estudar, dentro das normas de respeito à autonomia municipal, o caso de que determinadas municipalidades venham a solicitar, e em virtude de efetiva necessidade que o motivar, que a Administração-Geral facilite a prestação de alguma espécie de colaboração, inclusive fornecendo funcionários que dela se incumbam em adequado periodo de tempo.

A seguir na integra as notas dadas por «Fôlha de Minas» e «Correio do Ceará» que comprovam a repercussão obtida por nosso país.

\section{BRASIL APRESENTOU A MELHOR TESE EM LISBOA}

Os vereadores Nilson Gontijo é José Greco representaram Belo Horizonte no II Congresso de Municípios Ibero-americanos, realizado em Lisboa, parecido ontem à reunião da Câmara Municipal.

Falando à reportam de «Fôlha de Minas» aquêles dois edis tiveram ensejo de afirmar que o Brasil brilhou no conclave de Lisboa. Com uma bancada de 15 delegados, liderada pelo verador de Santos, Sr. Sílvio Fortunato, coube-lhe a apresentação da melhor tese do certame, pelo menos, a mais comentada e louvada pela imprensa lisboeta. O seu autor foi o representante do D.A.S.P., Sr. Manoel Caetano Bandeira de Mello, versando sôbre tema administrativo ligado ao sistema de administração municipal brasileira. Trata-se do tema «Formação e seleção dos funcionários da administração 
local e formas de designação e meios adequados para promover o seu aperfeiçoamento».

Essa tese mereceu grande atenção dos delegados dos paises participantes do conclave, isto é, da Argentina, Espanha, Portugal, México, Equador, El Salvador, Venezuela, Pôrto Rico, Filipinas, Panamá e Cuba.

Os dois edis representantes de Belo Horizonte afirmaram ainda a «Fôlha de Minas» que por onde andaram - Portugal, Espanha, Itália e França - Brasil é mais ou menos conhecido, mas que Brasília é tão falada que chega mesmo a parecer que não é a Nova Capital de nosso País. Brasilia constitui motivo de grande curiosidade para o povo europeu, que a classifica de grande obra do atual Govêrno Federal.

\section{CONSAGRAÇAO AO NOSSO PAÍS NO CONGRESSO MUNICIPA- LISTA DE LISBOA}

Regressou da Europa, onde participou, em Lisboa, do Congresso Hispano-Luso-Filipino dos Municípios, o deputado Almir Pinto, Presidente da Assembléia Legislativa, e representante do Brasil no importante conclave municipalista que reuniu delegações de todos os países centro e sul-americanos e mais da Espanha, de Portugal e das Filipinas.

\section{CONSAGRAÇÃO AO BRASIL}

Falando hoje pela manhã à reportagem do «Correio do Ceará», o deputado Almir PINTo disse, inicialmente:

- «O Congresso Hispano-Luso-Americano-Filipino, realizado em Portugal e na Espanha, teve o mérito primeiro de consolidar as relações de amizade que, tradicionalmente, unem os nossos países. Foi realizada ali uma aproximação de idéias de povos irmanados pelos mesmos sentimentos. Para os brasileiros, de um modo especial, êsse certame serviu para mostrar o prestígio de nossa terra. Empolgou-nos e confortou-nos a consideração vibrante e unânime ao Brasil, cuja projeção internacional surpreende mesmo a quantos, dentro ou fora da vida pública brasileira, encaram o desenvolvimento nacional com espírito de dúvida.

No Congresso, se já existiam, anteriormente, essas manifestações de simpatia aos brasileiros, elas cresceram no sentido da exaltação ao nosso país, o que muito se deve ao trabalho de pesquisa que desenvolvemos à importância das bases que defendemos.»

\section{PRINCIPAIS INDICAÇÕES}

Reportando-se aos principais projetos apresentados ao Congresso pela delegação brasileira, afirmou o deputado Almir PINTO:

- «Em primeiro lugar, situo a indicação da inclusão da Espanha e de Portugal na Operação Pan-Americana, indicação que não foi minha, mas que tive a honrosa incumbência de defender. Fiz sentir que a Operação Pan- 
Americana representa um movimento contra o subdesenvolvimento e que, com essa indicação, prestávamos a nossa solidariedade à solução de igual problema das comunidades espanholas e portuguêsas. Foi aprovada a tese de que ficaria confiado ao Secretário Permanente da entidade o estudo sôbre a aceitação da Operação. Em segundo lugar, situo a tese sôbre a Preparação Técnica de tuncionários municipais, de autoria do Dr. Manoel Bandeira de Mello, alto funcionário do D.A.S.P., moço de uma inteligência brilhante e de profundos conhecimentos.»

\section{O CEARÁ NAS COMISSÕES}

E prosseguiu o deputado Almir Pinto:

- «Os representantes cearenses ao Congresso participaram da Comissão sôbre «Intercâmbio Municipal». O Dr. PAIS DE ANDRADE, Secretário do Interior e Justiça, que, aliás, pronunciou um aplaudido discurso em Lisboa, e eu, que tive a honra de falar em nome do Brasil, no encerramento do Congresso.

\section{EXCURSÃO}

Por último, o Presidente da Assembléia, indagado pela reportagem, se reportou à vida carissima na Europa, para concluir tecendo elogiosas referências aos Escritórios Comerciais do Brasil em Paris e Roma. Em Paris, é figura central do Escritório o jornalista Hermenegildo de Sá Cavalcante, jovem muito relacionado na capital francesa, e que proporcionou aos brasileiros um programa de visitas a fábricas. Elogiou o deputado Almir Pinto o trabalho diplomático daquele colaborador dos «Diários Associados». 